\title{
Avaliação de espécies de Costaceae para uso ornamental ${ }^{(1)}$
}

\author{
CARLOS EDUARDO FERREIRA DE CASTRO(2), SILVIA ROCHA MOREIRA(3), ANA CECÍLIA RIBEIRO DE CASTRO(4), \\ FERNANDA VIDIGAL DUARTE SOUZA(5), VIVIAN LOGES ${ }^{(6)}$, CHARLESTON GONÇALVES(7), \\ MARIA ANGÉLICA PASSOS DE C. COSTA ${ }^{(8)}$, LUCAS FERNANDES DE MOURA ${ }^{(9)}$
}

\begin{abstract}
RESUMO
Este trabalho teve como objetivos mensurar e avaliar características morfológicas e agronômicas de 12 espécies da família Costaceae do banco de germoplasma de Zingiberales ornamentais do Instituto Agronômico (IAC), visando à indicação de espécies de costáceas para uso ornamental, considerando as categorias para uso como flor de corte, hastes cortadas, plantas de vaso e paisagismo. Em condições de campo, foram avaliadas dez plantas de cada espécie, com idade de um ano. Para a caracterização morfológica, foram utilizados 28 caracteres e avaliou-se a longevidade pós-colheita das inflorescências. Com base nos dados avaliados, conclui-se que Costus lasius, C. productus, C. malortieanus, C. pictus, C. arabicus variegata, C. stenophyllus, C. pulverulentus, C. comosus var. bakeri, Cheilocostus speciosus variegata e Dimerocostus strobilaceus são espécies indicadas para paisagismo; Costus lasius, C. productus, C. malortieanus e C.arabicus variegata são espécies adequadas para cultivo em vasos; Costus pictus, C. stenophyllus, Cheilocostus speciosus variegata e Dimerocostus strobilaceus são espécies adequadas para cultivo em grandes recipientes ou paisagismo; Costus lasius, C. productus, C. arabicus, C. stenophyllus, C. comosus var. bakeri, C. scaber, Cheilocostus speciosus variegata e Dimerocostus strobilaceus são espécies adequadas para a produção de flores de corte; e Costus stenophyllus, C. pictus, Cheilocostus speciosus variegata e Dimerocostus strobilaceus são espécies que podem ser comercializadas como hastes foliares cortadas.
\end{abstract}

Palavras chave: Costus, Cheilocostus, Dimerocostus, flor tropical, flor de corte, planta de vaso, planta de jardim, caracterização morfológica.

\section{ABSTRACT}

\section{Evaluation of Costaceae species for ornamental use}

The aim of this work was to measure and evaluate morphological and agronomic characteristics of 12 Costaceae species from Instituto Agronômico de Campinas (IAC) Ornamentals Zingiberales Germplasm Bank. For morphological characterization were used 28 characters and was evaluated the inflorescence post-harvest longevity. As a characterization result, this work indicated Costaceae species for ornamental purposes, considering the usage categories as cut flower, cut stem, pot plant and landscape design. Under field conditions, 10 plants with one year old, of each one of the following species: Costus lasius Loes., C. productus Maas, C. malortieanus Wendl., C. pictus D. Don., C. arabicus L., C. arabicus L. variegata, C. stenophyllus Standley \& Williams, C. pulverulentus Presl., C. comosus (Jacquin) Roscoe var. bakeri (K. Schumann) Maas, C. scaber Ruiz \& Pavón, Cheilocostus speciosus (Koenig) J. E. Smith variegata and Dimerocostus strobilaceus Kuntze were evaluated. It was concluded that Costus lasius, C. productus, C. malortieanus, C. pictus, C. arabicus variegata, C. stenophyllus, C. pulverulentus, C. comosus var. bakeri, Cheilocostus speciosus variegata and Dimerocostus strobilaceus are indicated species for landscape design; Costus lasius, C. productus, C. malortieanus and C.arabicus variegata are appropriated species for pot plants; Costus pictus, C. stenophyllus, Cheilocostus speciosus variegata and Dimerocostus strobilaceus are appropriated species for landscape design and big pot plants; Costus lasius, C. productus, C. arabicus, C. stenophyllus, C. comosus var. bakeri, C. scaber, Cheilocostus speciosus variegata and Dimerocostus strobilaceus are appropriated species for cut flower and that Costus stenophyllus, C. pictus, Cheilocostus speciosus variegata e Dimerocostus strobilaceus could be commercialized as cut stems.

Keywords: Costus, Cheilocostus, Dimerocostus, tropical flower, cut flower, pot plant, landscape design, morphological characterization.

\footnotetext{
(1) Recebido para publicação em 21/04/2010 e aceito em 29/04/2011.

(2) Pesquisador Científico, Centro de Horticultura, Instituto Agronômico (IAC), CP 28, CEP 13001-970, Campinas-SP, E-mail: ccastro@iac.sp.gov.br. (3) Pesquisador Científico, Centro de Horticultura, Instituto Agronômico (IAC), CP 28, CEP 13001-970, Campinas-SP, E-mail: silviamoreira@apta. sp.gov.br.

(4) Pesquisador Científico, Embrapa Agroindústria Tropical (CNPAT), Rua Dra. Sara Mesquita, 2270, CEP: 60511-110, Fortaleza-CE . E-mail: cecilia@cnpat.embrapa.br.

(5) Pesquisador Científico, Embrapa Mandioca e Fruticultura Tropical (CNPMF), Cruz das Almas -BA . E-mail: fernanda@cnpmf.embrapa.br.

(6) Pesquisador Científico, Professora de Floricultura, Universidade Federal Rural de Pernambuco, Rua Dom Manuel de Medeiros, s/n, Recife-PE. E-mail: vloges@yahoo.com.

(7) Pesquisador Científico, PRDTA do Vale do Paraíba, UPD de Ubatuba, CEP 13001-970, Ubatuba-SP, E-mail: charleston@apta.sp.gov.br.

${ }^{(8)}$ Pesquisador Científico, Professora da Universidade Federal do Recôncavo Baiano, Cruz das Almas - BA. E-mail: angelica@ufrb.br.

${ }^{(9)}$ Engenheiro Agrônomo, Bolsista CNPq, Centro de Horticultura, Instituto Agronômico (IAC), CP 28, CEP 13001-970, Campinas-SP.
} 


\section{INTRODUÇ̃̃O}

A família Costaceae, separada de Zingiberaceae após estudos anatômicos de TOMLINSON (1962) confirmados por KRESS (1990) e HEYWOOD (1993), pertence à ordem Zingiberales. Decorrente dos trabalhos de SPECHET (2006), a família foi dividida em sete gêneros que compreendem de 120 a 150 espécies. Os gêneros são Costus, com o maior número de espécies (cerca de 80), Cheilocostus, Chamaecostus, Paracostus, Dimerocostus, Monocostus e Tapeinochilos. Esta família tem distribuição natural na América, África, Ásia e norte da Austrália, sendo pouco explorada economicamente apesar de seu potencial ornamental. De forma esporádica é possível encontrar algumas plantas no comércio, tanto como plantas de vaso, mudas para jardins, flores de corte ou plantas medicinais.

$\mathrm{O}$ interesse por algumas espécies como flor de corte é devido à grande durabilidade pós-colheita das inflorescências, enquanto o uso no paisagismo em vasos ou em canteiros está relacionado ao longo período de floração, à arquitetura da planta, à variação da textura, à forma e cor de folhas e inflorescências e à adaptação a diferentes locais de cultivo.

Para o uso como planta de vaso, GONÇALVES et al. (2005) recomendaram como adequadas a esse propósito as espécies Costus curvibracteatus, C. erythrophyllus, $C$. malortieanus, C. cuspidatus, C. lasius e C. amazonicus, recentemente reclassificada como Costus arabicus variegata.

Em face da escassez de referências sobre utilização das espécies que compõem a família Costaceae, foi objetivo deste trabalho mensurar e avaliar características morfológicas e agronômicas de 12 espécies desta família - dez espécies do gênero Costus, uma do gênero Cheilocostus e uma do gênero Dimerocostus - todas pertencentes ao banco de germoplasma de Zingiberales ornamentais do Instituto Agronômico (IAC). Como resultado dessa caracterização, o trabalho visa à indicação de espécies de costáceas para uso ornamental, considerando as categorias para uso como flor de corte, hastes cortadas, plantas de vaso e paisagismo.

\section{MATERIAL E MÉTODOS}

As avaliações foram efetuadas na coleção de Costaceae, do Instituto Agronômico (IAC). Essa coleção foi iniciada em 1991 e tem registrados 80 acessos, de 16 espécies de Costus, uma de Dimerocostus, duas de Cheilocostus, uma de Chamaecostus e uma de Tapeinochilos. A maioria dos acessos de Costus (70) são originários de coletas em regiões de ocorrência natural no Brasil. Os outros acessos, tanto Costus como demais gêneros representados no banco, são provenientes de intercâmbios com instituições de pesquisa.

Encontra-se instalada na Unidade de Pesquisa e Desenvolvimento de Ubatuba, do Polo Regional de Desenvolvimento Tecnológico dos Agronegócios do Vale do Paraíba/ APTA, situada no município de Ubatuba, Estado de São Paulo, na latitude $23^{\circ} 26^{\prime} 02^{\prime \prime} \mathrm{S}$, longitude $45^{\circ} 04^{\prime} 16^{\prime \prime} \mathrm{W}$, pluviosidade média anual de $2.700 \mathrm{~mm}$ e a 6 metros acima do nível do mar.

Em condições de campo, foram avaliadas dez plantas, com idade de um ano, de cada uma das seguintes espécies: Costus lasius Loes., C. productus Maas, C. malortieanus Wendl., C. pictus D. Don., C. arabicus L., C. arabicus L. variegata, C. stenophyllus Standley \& Williams, C. pulverulentus Presl., C. comosus (Jacquin) Roscoe var. bakeri (K. Schumann) Maas, C. scaber Ruiz \& Pavón, Cheilocostus speciosus (Koenig) J. E. Smith variegata e Dimerocostus strobilaceus Kuntze.

A caracterização morfológica foi feita com base nos caracteres hastes florais, folhas, inflorescências, flores, da florada e de pós-colheita de inflorescências: 1) Porte: baixo $(\leq 0,80 \mathrm{~m})$, médio $(0,81-1,60 \mathrm{~m})$, alto $(1,61-2,40 \mathrm{~m})$ ou gigante $(\geq 2,41 \mathrm{~m})$, medido com trena; 2) Hábito da planta: largo colunar, colunar ou expandido; 3) capacidade de recobrimento do solo (informação essencial para definir adequação de determinada espécie ao uso paisagístico, obtida sob o ponto de vista do observador a um metro de distância da planta): elevada (>60\%), média (60 a 30\%) ou baixa $(<30 \%)$; 4) Firmeza da haste: capacidade de manutenção da posição típica da espécie, anotando-se tombamento ou não da haste; 5) Diâmetro da haste: tomado a 20 $\mathrm{cm}$ abaixo do ápice da haste, medido com auxílio de paquímetro; 6) Organização espacial da haste: ereta, espiralada ou decumbente; 7) Comprimento da haste (cm): distância entre a porção basal e apical da haste, medido com régua graduada; 8) Coloração da haste: avaliada conforme cor ou cores predominantes na haste; 9) Pilosidade da haste: glabra (sem tricomas), pubescente (poucos tricomas $<1 \mathrm{~mm}$ ), velutina (muitos tricomas aveludados $<1 \mathrm{~mm}$ ), tomentosa (muitos tricomas aveludados entre $1 \mathrm{~mm}$ e $3 \mathrm{~mm}$ ), hirsuta (poucos tricomas aveludados entre $1 \mathrm{~mm}$ e $3 \mathrm{~mm}$ ); 10) Lígula: evidente, pouco evidente; 11) Número de hastes por planta; 12) Formato das folhas: elíptica, largo-elíptica, estreito-eliptica, linear, oblonga; 13) Largura e comprimento das folhas $(\mathrm{cm})$ : uso de régua graduada, em folha selecionada na porção mediana da haste vegetativa; 14) Pilosidade das folhas: glabra (sem tricomas), pubescente (poucos tricomas $<1 \mathrm{~mm}$ ), velutina (muitos tricomas aveludados $<1 \mathrm{~mm}$ ), tomentosa (muitos tricomas aveludados entre $1 \mathrm{~mm}$ e $3 \mathrm{~mm}$ ), hirsuta (poucos tricomas aveludados entre $1 \mathrm{~mm}$ e $3 \mathrm{~mm}$ ); 15) Presença de variegação na folha; 16) Coloração predominante das faces superior e inferior da folha; 17) Relação folhas verdes/folhas secas: maior presença de folhas verdes: alta $(>70 \%)$, média (entre 40 e $70 \%$ ), baixa $(<40 \%)$; 18) Posicionamento da inflorescência: terminal ou basal; 19) Número de inflorescência por planta: baixo $(<3)$, médio (entre 3 e 6 ) e elevado $(>6)$; 20) Formato da inflorescência: ovóide, ovóide a fusiforme, fusiforme, fusiforme a ovóide, globosa, taça; 21) Comprimento e largura da inflorescência $(\mathrm{cm})$ : uso de régua graduada; 22) Imbricamento da inflorescência: brácteas justapostas ou brácteas expandidas (livres); 23) Coloração das brácteas: cor ou cores predominantes na face externa das brácteas da inflorescência; 24) Formato da flor (cálice e corola fechados): cônicas, tubulares, tubulares a cônicas, arredondadas; 25) Comprimento e largura da flor (cm): tomado com régua graduada, na porção mediana da flor; 26) Coloração do conjunto cálice/corola/labelo e abertura floral: consideraram-se para as avaliações de coloração, a cor predominante no conjunto e as especificidades de cor no cálice, na corola e no labelo. Em termos de abertura 
foram consideradas flores densas (fechadas) ou abertas (peças florais expandidas); 27) Período de floração: espaço de tempo entre início e término do evento, nas condições climáticas locais e materiais avaliados de cada espécie; 28) Duração da floração (espaço de tempo entre surgimento e senescência de cada inflorescência): alta ( $>45$ dias), média (entre 30 e 45 dias) ou baixa ( $<30$ dias).

Avaliação de durabilidade pós-colheita: Para a avaliação de durabilidade pós-colheita, foram obtidos dados sobre a manutenção de flores e necessidade de limpeza das inflorescências e durabilidade após o corte. A manutenção de flores nas inflorescências considerou a permanência da flor senescente no interior das brácteas. A necessidade de limpeza foi parâmetro decorrente da persistência de flores nas inflorescências.

Para as avaliações de durabilidade pós-colheita, as inflorescências utilizadas passaram por processos subsequentes de lavagem e imersão em água limpa, por duas horas após o corte e, posteriormente, foram mantidas em frascos com $500 \mathrm{~mL}$ de água, em laboratório, sob temperatura de $21^{\circ} \mathrm{C}$. Foram avaliadas a cada dois dias, mensurado o número total de dias (durabilidade global) da inflorescência do dia do corte até surgimento dos primeiros sinais de senescência (murcha, perda de brilho, enrolamento e secamento do ápice das brácteas). Foram adotados os seguintes períodos: longo (> 20 dias), médio (entre 10 e 20 dias) e baixo $(<10$ dias $)$.

Para a indicação de uso, foi feita uma análise do con- junto das características e atributos avaliados. Foram consideradas, para cada categoria de uso, as seguintes características:

a) Plantas de vaso: porte baixo e arquitetura da planta uniforme, manutenção de folhas verdes ou variegadas nas hastes, alta capacidade de recobrimento do solo, coloração e dimensões das hastes foliares e folhas e características da floração, persistência e período, incluindo o número de inflorescências produzidas por ciclo.

b) Plantas para jardim e paisagismo: porte alto da planta, alta capacidade de recobrimento do solo, coloração, dimensões das hastes foliares e folhas e características da floração, duração e período e número de inflorescências produzidas por ciclo.

c) Plantas para uso como flor de corte: tamanho grande da haste, alta durabilidade das inflorescências, não persistência das flores e consequente eliminação da necessidade da retirada delas no interior das brácteas e número de flores por planta ou touceira e ciclo.

\section{RESULTADOS E DISCUSSÃO}

Foi observada grande variação fenotípica entre as espécies com relação às características gerais da planta (Tabela 1), das hastes foliares (Tabela 2), das folhas (Tabela 3 ), das inflorescências (Tabela 4), das flores (Tabela 5) e das características da floração e da pós-colheita das inflorescências (Tabela 6).

Tabela 1. Características gerais da planta de espécies de Costaceae. Ubatuba/SP, 2009.

Table 1. General characteristics of Costaceae species. Ubatuba / SP, 2009.

\begin{tabular}{|c|c|c|c|c|c|c|}
\hline \multirow[b]{2}{*}{ Espécie } & \multicolumn{6}{|c|}{ Características das plantas } \\
\hline & $\begin{array}{l}\text { Porte } \\
\text { (m) }\end{array}$ & Hábito & $\begin{array}{l}\text { Capacidade de } \\
\text { recobrimento } \\
\text { do solo }\end{array}$ & $\begin{array}{l}\text { Firmeza das } \\
\text { hastes }\end{array}$ & $\begin{array}{l}\text { Relação folhas } \\
\text { verdes e folhas } \\
\text { secas }\end{array}$ & $\begin{array}{c}\text { Inflorescências } \\
\text { por planta } \\
\left(n^{\circ}\right)\end{array}$ \\
\hline Costus lasius & $\begin{array}{c}0,67-0,7 \\
\text { (baixo) }\end{array}$ & expandido & elevada & firme & alta & elevado \\
\hline $\begin{array}{c}\text { Costus } \\
\text { productus }\end{array}$ & $\begin{array}{l}0,97 \text { a } 1,0 \\
\text { (médio) }\end{array}$ & expandido & elevada & firme & alta & elevado \\
\hline $\begin{array}{c}\text { Costus } \\
\text { malortieanus }\end{array}$ & $\begin{array}{c}0,59 \text { a } 1,32 \\
\text { (baixo a médio) }\end{array}$ & expandido & elevada & firme & média & médio \\
\hline Costus pictus & $\begin{array}{c}1,3 \text { a } 2,0 \\
\text { (médio a alto) }\end{array}$ & colunar & elevada & firme & alta & médio \\
\hline $\begin{array}{c}\text { Costus arabicus } \\
\text { variegata }\end{array}$ & $\begin{array}{l}0,32 \text { a } 0,58 \\
\text { (baixo) }\end{array}$ & expandido & média & tombamento & alta & baixo \\
\hline Costus arabicus & $\begin{array}{l}1,0 \text { a } 1,6 \\
\text { (médio) }\end{array}$ & colunar & baixa & firme & baixa & baixo \\
\hline $\begin{array}{c}\text { Costus } \\
\text { stenophyllus }\end{array}$ & $\begin{array}{c}1,73 \text { a } 2,1 \\
\text { (médio a alto) }\end{array}$ & colunar & média & firme & alta & baixo \\
\hline $\begin{array}{c}\text { Costus } \\
\text { pulverulentus }\end{array}$ & $\begin{array}{c}1,38 \text { a } 1,96 \\
\text { (médio a alto) }\end{array}$ & colunar & baixa & firme & alta & médio \\
\hline $\begin{array}{l}\text { Costus comosus } \\
\text { var. bakeri }\end{array}$ & $\begin{array}{c}1,2 \text { a } 1,88 \\
\text { (médio a alto) }\end{array}$ & largo-colunar & baixa & firme & alta & baixo \\
\hline Costus scaber & $\begin{array}{c}1,4 \text { a } 2,0 \\
\text { (médio a alto) }\end{array}$ & colunar & baixa & firme & média & baixo \\
\hline $\begin{array}{c}\text { Cheilocostus } \\
\text { speciosus } \\
\text { variegata }\end{array}$ & $\begin{array}{c}1,53 \text { a } 1,92 \\
\text { (médio a alto) }\end{array}$ & largo-colunar & média a elevada & firme & alta & $\begin{array}{l}\text { médio a } \\
\text { elevado }\end{array}$ \\
\hline $\begin{array}{c}\text { Dimerocostus } \\
\text { strobilaceus }\end{array}$ & $\begin{array}{l}2,6 \text { a } 3,5 \\
\text { (gigante) }\end{array}$ & colunar & média & firme & alta & elevado \\
\hline
\end{tabular}


Tabela 2. Características de hastes foliares de espécies de Costaceae. Ubatuba/SP, 2009.

Table 2. Stem leaf characteristics of Costaceae species. Ubatuba / SP, 2009.

\begin{tabular}{|c|c|c|c|c|c|c|c|}
\hline \multirow[b]{2}{*}{ Espécie } & \multicolumn{7}{|c|}{ Características das hastes foliares } \\
\hline & $\begin{array}{c}\text { Organização } \\
\text { Espacial }\end{array}$ & $\begin{array}{l}\text { Diâmetro } \\
(\mathrm{cm})\end{array}$ & $\begin{array}{c}\text { Comprimento } \\
(\mathrm{m})\end{array}$ & Coloração & Pilosidade & Lígula & $\begin{array}{l}\text { Hastes por } \\
\text { planta }\left(\mathrm{n}^{\circ}\right)\end{array}$ \\
\hline Costus lasius & espiralada & 0,4 a 0,5 & 0,6 a 0,7 & verde & tomentosa & evidente & acima de 40 \\
\hline $\begin{array}{c}\text { Costus } \\
\text { productus }\end{array}$ & ereta & 1,1 a 1,3 & 0,9 a 1,1 & verde & glabra & evidente & $28-37$ \\
\hline $\begin{array}{c}\text { Costus } \\
\text { malortieanus }\end{array}$ & ereta & 1,5 a 2,0 & 0,5 a 0,8 & $\begin{array}{c}\text { verde com } \\
\text { faixas marrom }\end{array}$ & velutina & evidente & $5-7$ \\
\hline Costus pictus & ereta & 0,7 a 1,3 & 0,5 a 2,5 & $\begin{array}{c}\text { verde com } \\
\text { faixas vinho }\end{array}$ & glabra & pouco evidente & $18-40$ \\
\hline $\begin{array}{c}\text { Costus arabicus } \\
\text { variegata }\end{array}$ & $\begin{array}{l}\text { decumbente } \\
\text { (levemente) }\end{array}$ & 0,4 a 0,5 & 0,3 a 0,5 & verde & glabra & pouco evidente & $4-8$ \\
\hline Costus arabicus & ereta & 0,4 a 0,5 & 0,4 a 1,1 & verde & glabra & pouco evidente & $3-5$ \\
\hline $\begin{array}{c}\text { Costus } \\
\text { stenophyllus }\end{array}$ & ereta & 0,5 a 0,7 & 1,7 a 2,0 & $\begin{array}{c}\text { cinza com } \\
\text { faixas marrom }\end{array}$ & glabra & evidente & $19-22$ \\
\hline $\begin{array}{c}\text { Costus } \\
\text { pulverulentus }\end{array}$ & ereta & 0,7 a 1,0 & 0,9 a 1,8 & verde & glabra & evidente & $7-11$ \\
\hline $\begin{array}{l}\text { Costus comosus } \\
\text { var. bakeri }\end{array}$ & ereta & 1,7 a 1,9 & 1,3 a 2,0 & verde & glabra & evidente & $7-8$ \\
\hline Costus scaber & ereta & 0,5 a 1,2 & 1,1 a 1,8 & verde & glabra & pouco evidente & $5-8$ \\
\hline $\begin{array}{c}\text { Cheilocostus } \\
\text { speciosus } \\
\text { variegata }\end{array}$ & $\begin{array}{c}\text { espiralada a } \\
\text { ereta }\end{array}$ & 0,7 a 1,4 & 1,5 a 1,8 & $\begin{array}{l}\text { variegação } \\
\text { rosa, verde e } \\
\text { branco }\end{array}$ & velutina & pouco evidente & $11-25$ \\
\hline $\begin{array}{c}\text { Dimerocostus } \\
\text { strobilaceus }\end{array}$ & ereta & 2,5 a 3,0 & 2,6 a 3,5 & $\begin{array}{c}\text { verde com } \\
\text { faixas marrom }\end{array}$ & glabra & evidente & $15-19$ \\
\hline
\end{tabular}

Tabela 3. Características de folhas de espécies de Costaceae. Ubatuba/SP, 2009.

Table 3. Leaves characteristics of Costaceae species. Ubatuba / SP, 2009.

\begin{tabular}{|c|c|c|c|c|c|c|c|}
\hline \multirow[b]{2}{*}{ Espécie } & \multicolumn{7}{|c|}{ Características das folhas } \\
\hline & Forma & $\begin{array}{l}\text { Comprimento } \\
\text { (cm) }\end{array}$ & $\begin{array}{l}\text { Largura } \\
(\mathrm{cm})\end{array}$ & Pilosidade & Variegação & $\begin{array}{c}\text { Coloração da } \\
\text { face adaxial }\end{array}$ & $\begin{array}{l}\text { Coloração da } \\
\text { face abaxial }\end{array}$ \\
\hline Costus lasius & elíptica & $9,5-11,0$ & $3,0-3,5$ & tomentosa & sem variegação & $\begin{array}{c}\text { verde com } \\
\text { pontos escuros }\end{array}$ & verde \\
\hline Costus productus & elíptica & $24,0-26,0$ & $4,0-8,0$ & $\begin{array}{c}\text { glabra em ambas } \\
\text { as faces- }\end{array}$ & sem variegação & $\begin{array}{c}\text { verde com } \\
\text { pontos escuros }\end{array}$ & verde claro \\
\hline $\begin{array}{c}\text { Costus } \\
\text { malortieanus }\end{array}$ & $\begin{array}{l}\text { largo- } \\
\text { eliptica }\end{array}$ & $31,0-34,0$ & $\begin{array}{c}15,5- \\
19,0\end{array}$ & velutina & sem variegação & $\begin{array}{c}\text { verde com } \\
\text { faixas escuras }\end{array}$ & cinza \\
\hline Costus pictus & $\begin{array}{l}\text { linear a } \\
\text { elíptica }\end{array}$ & $18,0-38,0$ & $2,0-4,0$ & $\begin{array}{c}\text { glabra em ambas } \\
\text { as faces }\end{array}$ & sem variegação & verde & verde \\
\hline $\begin{array}{c}\text { Costus arabicus } \\
\text { variegata }\end{array}$ & elíptica & $9,0-9,5$ & $3,5-4,0$ & $\begin{array}{c}\text { glabra em ambas } \\
\text { as faces }\end{array}$ & $\begin{array}{l}\text { variegação } \\
\text { irregular verde } \\
\text { e creme }\end{array}$ & verde e creme & verde e creme \\
\hline Costus arabicus & elíptica & $8,0-15,0$ & $3,8-6,0$ & $\begin{array}{c}\text { glabra na face } \\
\text { adaxial/velutina } \\
\text { na face abaxial }\end{array}$ & sem variegação & verde & verde \\
\hline $\begin{array}{c}\text { Costus } \\
\text { stenophyllus }\end{array}$ & linear & $24,0-25,5$ & $2,0-2,5$ & $\begin{array}{l}\text { hirsuta na face } \\
\text { adaxial/glabra na } \\
\text { face abaxial }\end{array}$ & sem variegação & verde & verde \\
\hline $\begin{array}{c}\text { Costus } \\
\text { pulverulentus }\end{array}$ & elíptica & $19,0-25,3$ & $7,5-8,0$ & $\begin{array}{c}\text { glabra em ambas } \\
\text { as faces- }\end{array}$ & sem variegação & $\begin{array}{c}\text { verde com } \\
\text { pontos escuros }\end{array}$ & verde \\
\hline $\begin{array}{l}\text { Costus comosus } \\
\text { var. bakeri }\end{array}$ & elíptica & $33,0-39,0$ & $2,5-6,5$ & $\begin{array}{c}\text { glabra na face } \\
\text { adaxial/velutina } \\
\text { na face abaxial }\end{array}$ & sem variegação & verde & $\begin{array}{c}\text { verde } \\
\text { acinzentado }\end{array}$ \\
\hline Costus scaber & $\begin{array}{l}\text { estreito- } \\
\text { elíptica }\end{array}$ & $15,0-22,0$ & $6,0-10,0$ & $\begin{array}{c}\text { glabra em ambas } \\
\text { as faces- }\end{array}$ & sem variegação & verde & verde \\
\hline $\begin{array}{l}\text { Cheilocostus } \\
\text { speciosus } \\
\text { variegata }\end{array}$ & $\begin{array}{l}\text { estreito- } \\
\text { elíptica }\end{array}$ & $17,0-30,0$ & $4,0-8,5$ & $\begin{array}{c}\text { glabra na face } \\
\text { adaxial/velutina } \\
\text { na face abaxial }\end{array}$ & $\begin{array}{l}\text { variegação em } \\
\text { faixas verde e } \\
\text { creme }\end{array}$ & verde e creme & $\begin{array}{l}\text { verde e creme, } \\
\text { acinzentada }\end{array}$ \\
\hline $\begin{array}{c}\text { Dimerocostus } \\
\text { strobilaceus }\end{array}$ & $\begin{array}{l}\text { elíptica a } \\
\text { linear }\end{array}$ & $52,0-63,0$ & $3,5-10,0$ & $\begin{array}{c}\text { glabra na face } \\
\text { adaxial/velutina } \\
\text { na face abaxial }\end{array}$ & sem variegação & $\begin{array}{c}\text { verde } \\
\text { acinzentado }\end{array}$ & verde \\
\hline
\end{tabular}


Tabela 4. Características de inflorescências de espécies de Costaceae. Ubatuba/SP, 2009.

Table 4. Inflorescence characteristics of Costaceae species. Ubatuba / SP, 2009.

\begin{tabular}{|c|c|c|c|c|c|c|}
\hline \multirow[b]{2}{*}{ Espécie } & \multicolumn{6}{|c|}{ Características das inflorescências } \\
\hline & $\begin{array}{c}\text { Posicionamento } \\
\text { na haste }\end{array}$ & Forma & $\begin{array}{l}\text { Comprimento } \\
(\mathrm{cm})\end{array}$ & $\begin{array}{l}\text { Largura } \\
(\mathrm{cm})\end{array}$ & $\begin{array}{l}\text { Imbricamento } \\
\text { das brácteas }\end{array}$ & $\begin{array}{c}\text { Cor externa das } \\
\text { brácteas }\end{array}$ \\
\hline Costus lasius & terminal & $\begin{array}{l}\text { ovóide a } \\
\text { fusiforme }\end{array}$ & $6,5-7,0$ & $2,0-2,5$ & justapostas & amarelo \\
\hline Costus productus & terminal & taça & $5,0-9,0$ & $2,3-4,5$ & expandidas & $\begin{array}{l}\text { laranja e } \\
\text { vermelho }\end{array}$ \\
\hline $\begin{array}{c}\text { Costus } \\
\text { malortieanus }\end{array}$ & terminal & globosa & $7,5-12,0$ & $3,5-4,0$ & justapostas & verde \\
\hline Costus pictus & terminal e basal & globosa & $10,0-15,0$ & $3,0-3,3$ & justapostas & verde \\
\hline $\begin{array}{c}\text { Costus arabicus } \\
\text { variegata }\end{array}$ & terminal & $\begin{array}{l}\text { ovóide a } \\
\text { fusiforme }\end{array}$ & $3,0-8,0$ & $3,0-4,0$ & justapostas & verde \\
\hline Costus arabicus & terminal & $\begin{array}{l}\text { ovóide a } \\
\text { fusiforme }\end{array}$ & $7,0-12,0$ & $3,0-6,0$ & justapostas & verde \\
\hline $\begin{array}{c}\text { Costus } \\
\text { stenophyllus }\end{array}$ & basal & fusiforme & $10,0-14,0$ & $2,0-3,0$ & justapostas & $\begin{array}{l}\text { laranja a } \\
\text { vermelho }\end{array}$ \\
\hline $\begin{array}{c}\text { Costus } \\
\text { pulverulentus }\end{array}$ & terminal & fusiforme & $6,0-7,5$ & $2,3-2,7$ & justapostas & vermelho \\
\hline $\begin{array}{l}\text { Costus comosus } \\
\text { var. bakeri }\end{array}$ & terminal & fusiforme & $6,0-15,0$ & $4,5-5,5$ & $\begin{array}{l}\text { justapostas mas } \\
\text { livres no ápice }\end{array}$ & $\begin{array}{l}\text { laranja a } \\
\text { vermelho }\end{array}$ \\
\hline Costus scaber & terminal & fusiforme & $10,0-14,0$ & $2,5-4,0$ & justapostas & $\begin{array}{l}\text { laranja a } \\
\text { vermelho }\end{array}$ \\
\hline $\begin{array}{c}\text { Cheilocostus } \\
\text { speciosus } \\
\text { variegata }\end{array}$ & terminal & $\begin{array}{l}\text { ovóide a } \\
\text { fusiforme }\end{array}$ & $4,5-16,0$ & $2,4-6,0$ & justapostas & vinho \\
\hline $\begin{array}{c}\text { Dimerocostus } \\
\text { strobilaceus }\end{array}$ & terminal & $\begin{array}{c}\text { fusiforme a } \\
\text { ovóide }\end{array}$ & $18,0-30,0$ & $4,0-6,0$ & $\begin{array}{c}\text { justapostas } \\
\text { (frouxamente) }\end{array}$ & $\begin{array}{c}\text { marrom } \\
\text { acinzentado }\end{array}$ \\
\hline
\end{tabular}

Tabela 5. Características das flores de espécies de Costaceae. Ubatuba/SP, 2009.

Table 5. Flowers characteristics of Costaceae species. Ubatuba / SP, 2009.

\begin{tabular}{|c|c|c|c|c|c|}
\hline \multirow[b]{2}{*}{ Espécie } & \multicolumn{5}{|c|}{ Características das flores } \\
\hline & Formato & $\begin{array}{l}\text { Comprimento } \\
(\mathrm{cm})\end{array}$ & $\begin{array}{l}\text { Largura } \\
(\mathrm{cm})\end{array}$ & Cor & abertura \\
\hline Costus lasius & cônico & $2,0-4,0$ & $1,0-2,0$ & amarelo & densa \\
\hline Costus productus & cônico & $1,0-3,5$ & $1,0-2,0$ & laranja & densa \\
\hline Costus malortieanus & tubular & $5,5-6,0$ & $2,0-3,0$ & $\begin{array}{l}\text { rosa amarelado, } \\
\text { listas vermelhas } \\
\text { internamente e } \\
\text { labelo amarelo }\end{array}$ & aberta \\
\hline Costus pictus & tubular & $4,0-6,0$ & $3,0-4,0$ & $\begin{array}{l}\text { creme a amarelo } \\
\text { com labelo } \\
\text { avermelhado }\end{array}$ & aberta \\
\hline $\begin{array}{c}\text { Costus arabicus } \\
\text { variegata }\end{array}$ & tubular & $3,0-5,0$ & $2,0-3,0$ & $\begin{array}{l}\text { branco com faixas } \\
\text { amarelas no labelo }\end{array}$ & aberta \\
\hline Costus arabicus & tubular & $3,0-6,0$ & $2,0-4,0$ & $\begin{array}{c}\text { branco com rosa ou } \\
\text { verde }\end{array}$ & aberta \\
\hline Costus stenophyllus & tubular a cônico & $2,0-5,0$ & $1,0-3,0$ & amarelo & densa \\
\hline Costus pulverulentus & cônico & $6,0-10,0$ & $1,0-2,0$ & vermelho a laranja & densa \\
\hline $\begin{array}{c}\text { Costus comosus var. } \\
\text { bakeri }\end{array}$ & cônico & $3,0-4,0$ & $1,5-2,0$ & amarelo & densa \\
\hline Costus scaber & cônico & $2,5-4,0$ & $1,5-2,0$ & laranja a vermelho & densa \\
\hline $\begin{array}{c}\text { Cheilocostus } \\
\text { speciosus variegata }\end{array}$ & arredondado & $7,0-8,0$ & $7,0-8,0$ & $\begin{array}{l}\text { branco com centro } \\
\text { amarelo e cálice } \\
\text { vermelho a verde }\end{array}$ & aberta \\
\hline $\begin{array}{l}\text { Dimerocostus } \\
\text { strobilaceus }\end{array}$ & arredondado & $8,0-10,0$ & $8,0-10,0$ & branco & aberta \\
\hline
\end{tabular}


Tabela 6. Características da floração e da pós-colheita de inflorescências de espécies de Costaceae. Ubatuba/SP, 2009. Table 6. Flowering and post-harvest characteristics of Costaceae species. Ubatuba / SP, 2009.

\begin{tabular}{|c|c|c|c|c|c|}
\hline \multirow[b]{2}{*}{ Espécie } & \multicolumn{2}{|c|}{ Características da floração } & \multicolumn{3}{|c|}{ Características de pós-colheita } \\
\hline & Duração da florada & Período & $\begin{array}{c}\text { Persistência } \\
\text { das flores na } \\
\text { inflorescência }\end{array}$ & $\begin{array}{l}\text { Necessidade } \\
\text { de limpeza das } \\
\text { inflorescências }\end{array}$ & $\begin{array}{c}\text { Durabilidade das } \\
\text { inflorescências }\end{array}$ \\
\hline Costus lasius & alta & agosto/fevereiro & não & não & longa \\
\hline Costus productus & alta & agosto/maio & não & não & longa \\
\hline Costus malortieanus & alta & agosto/maio & $\operatorname{sim}$ & $\operatorname{sim}$ & baixa \\
\hline Costus pictus & média & setembro/novembro & não & não & baixa \\
\hline $\begin{array}{c}\text { Costus arabicus } \\
\text { variegata }\end{array}$ & baixa & setembro/novembro & não & não & baixa \\
\hline Costus arabicus & média & agosto/fevereiro & não & não & média \\
\hline Costus stenophyllus & alta & agosto/dezembro & não & não & média \\
\hline $\begin{array}{c}\text { Costus } \\
\text { pulverulentus }\end{array}$ & alta & junho/fevereiro & não & não & longa \\
\hline $\begin{array}{c}\text { Costus comosus var. } \\
\text { bakeri }\end{array}$ & alta & setembro/junho & não & não & longa \\
\hline Costus scaber & média & setembro/março & não & não & longa \\
\hline $\begin{array}{c}\text { Cheilocostus } \\
\text { speciosus variegata }\end{array}$ & alta & setembro/maio & $\operatorname{sim}$ & $\operatorname{sim}$ & longa \\
\hline $\begin{array}{l}\text { Dimerocostus } \\
\text { strobilaceus }\end{array}$ & média & setembro/dezembro & não & não & média \\
\hline
\end{tabular}

Os dados obtidos referentes a características morfológicas das espécies foram compatíveis com aqueles das descrições botânicas de MAAS $(1972,1976)$ e SPECHT e STEVENSON (2006).

Em função do porte da planta, capacidade de recobrimen- to do solo, coloração, dimensões das hastes foliares e folhas e as características da floração (duração, período e número de inflorescências produzidas por ciclo), observou-se que as espécies avaliadas são indicadas para uso em jardins, exceto as espécies C. arabicus (Figura 1) e C. scaber (Figura 2).
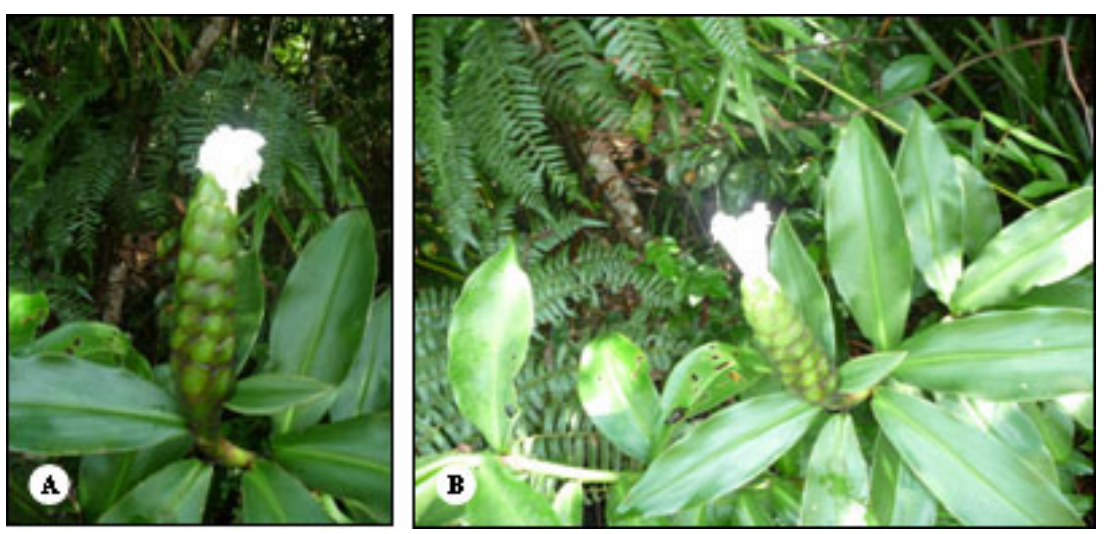

Figura 1. Costus arabicus: a) inflorescência; b) aspecto geral da planta.

Figure 1. Costus arabicus: a) inflorescence; b) overview of plant.
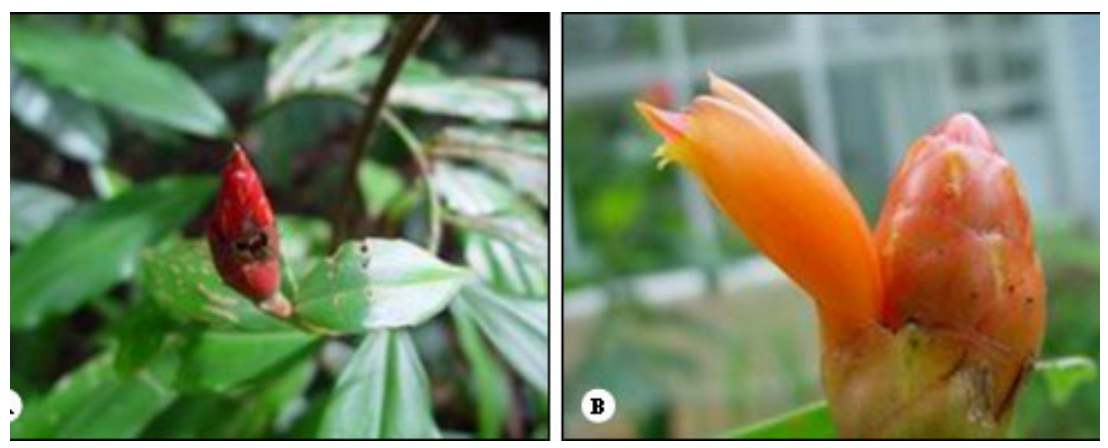

Figura 2. Costus scaber: a) aspecto geral da planta; b) inflorescência.

Figure 2. Costus scaber: a) overview of plant; b) inflorescence. 
As plantas de C. lasius (Figura 3) apresentam porte baixo, hábito da planta expandido, distribuição espiralada da folhagem e elevado número de hastes foliares por planta, permitindo uma alta capacidade de recobrimento do solo. Além disso, foi observada uma alta persistência de folhas verdes e inflorescências nas plantas, grande núme- ro de inflorescências por planta, longo período da florada bem como contraste entre cor da inflorescência e folhagem. Ademais, as inflorescências apresentam longa vida póscolheita. Essas características permitem sua recomendação como flor de corte, planta de vaso e planta para jardim e paisagismo.
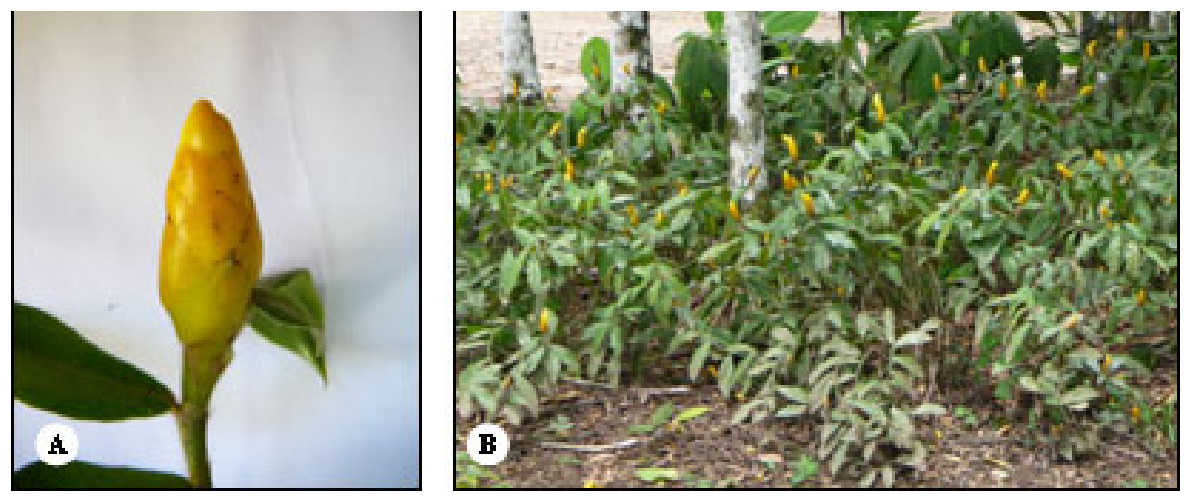

Figura 3. Costus lasius: a) inflorescência; b) aspecto geral da planta.

Figure 3. Costus lasius: a) inflorescence; b) overview of plant.

C. productus (Figura 4) apresenta plantas de porte médio e hábito expandido. Percebe-se que o elevado número de hastes foliares por planta permite uma alta capacidade de recobrimento do solo. A espécie apresenta excelente persistência de folhas verdes nas plantas, alto número de inflorescências em forma de taça, longo período da florada e interessante contraste entre cor da inflorescência e folhagem. Entre as espécies avaliadas, $C$. productus apresentou florescimento por cerca de dez meses, superior a todas as outras espécies avaliadas, característica que a torna adequada tanto como planta de vaso, como para planta de jardim e paisagismo. A longa longevidade pós-colheita de suas inflorescências permite recomendá-la também como flor de corte.

As principais características de C. malortieanus (Figura 5) foram o porte baixo a médio da planta e o hábito expandido. As grandes dimensões e textura das folhas, embora em menor número de hastes foliares, permitem uma alta capacidade de recobrimento do solo. Outro aspecto de destaque é o longo período da florada. Além da beleza, o aspecto arredondado das plantas, em conjunto, confere a esta espécie um excelente potencial paisagístico.
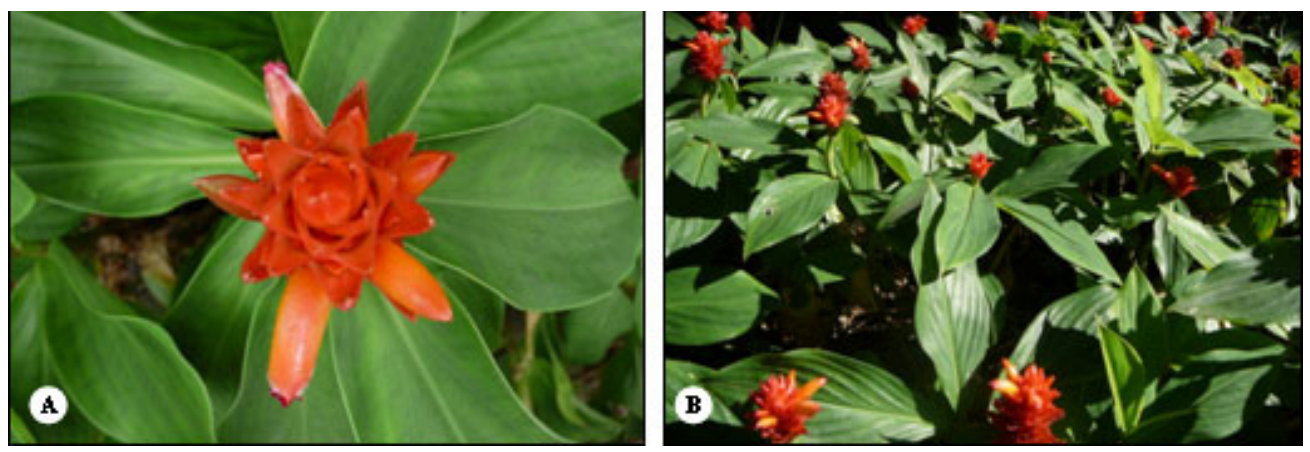

Figura 4. Costus productus: a) inflorescência; b) aspecto geral da planta. Figure 4. Costus productus: a) inflorescence; b) overview of plant.
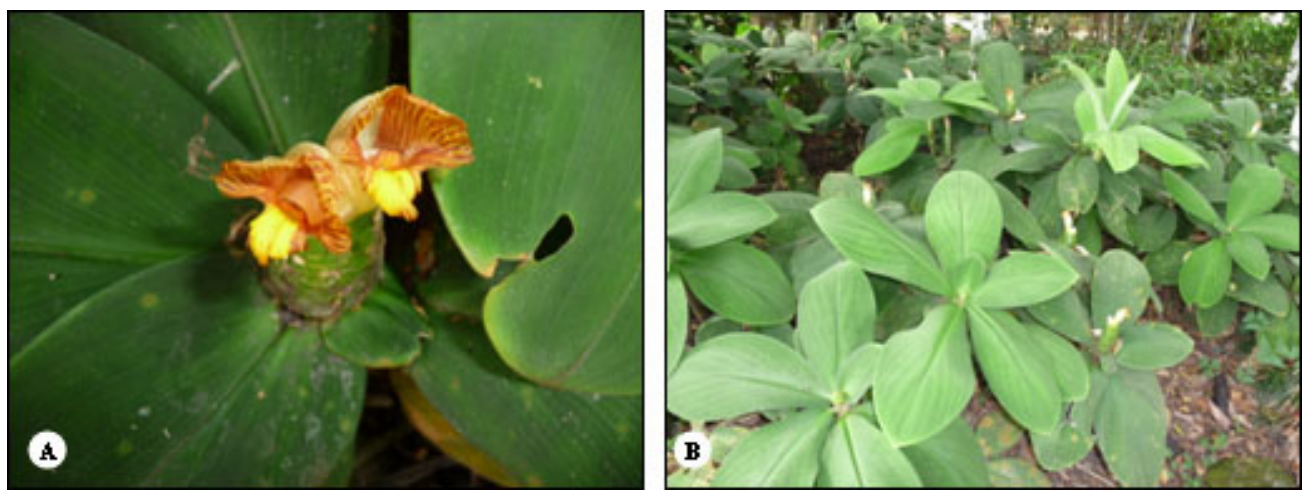

Figura 5. Costus malortieanus: a) inflorescência; b) aspecto geral da planta.

Figure 5. Costus malortieanus: a) inflorescence; b) overview of plant. 
C. pictus (Figura 6) apresenta grande número de hastes foliares por planta, que formam uma touceira maciça e permitem um bom recobrimento do solo. A coloração das hastes florais, verde com listas vinho, e o hábito colunar da planta, porte alto, persistência das folhas lineares por longo período e inflorescências globosas, tanto basais como terminais, permitem sua indicação para uso em jardins.

C. arabicus variegata (Figura 7) de porte baixo e hábito expandido apresenta baixa capacidade de cobertura do solo decorrente da emissão de poucas hastes foliares levemente decumbentes. Possivelmente em plantios adensados dessa espécie, esta dificuldade seja facilmente superada. Entretanto, face às suas exóticas folhas variegadas em verde e creme, mantidas por longo período, esta espécie pode ser caracterizada como exuberante e muito atraente, com elevado potencial de uso em jardins tropicais que necessitam de espécies de sombra, que possam fazer contraste de cor e textura com as outras folhagens.
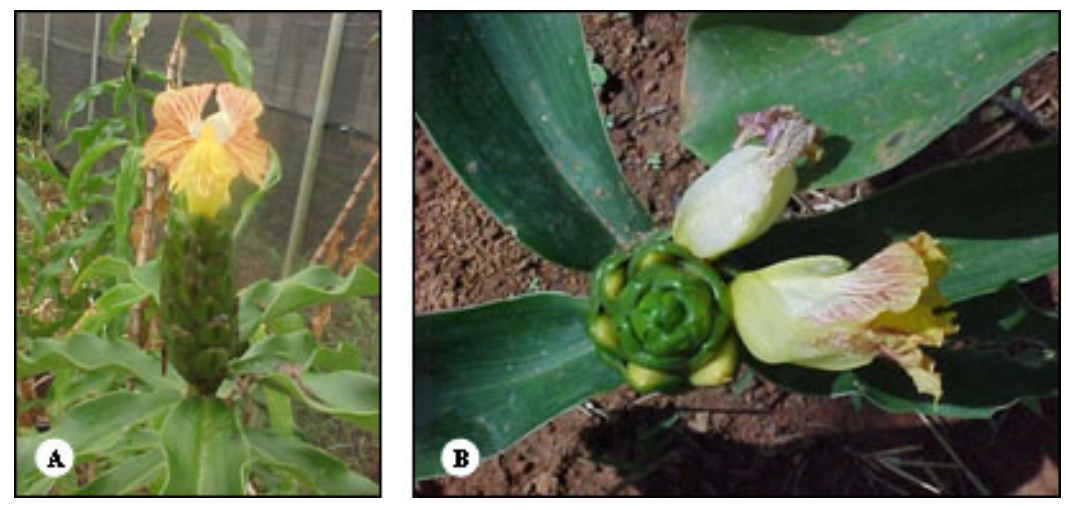

Figura 6. Costus pictus: a) inflorescência; b) inserção da flor.

Figure 6. Costus pictus: a) inflorescence; b) insertion of the flower.
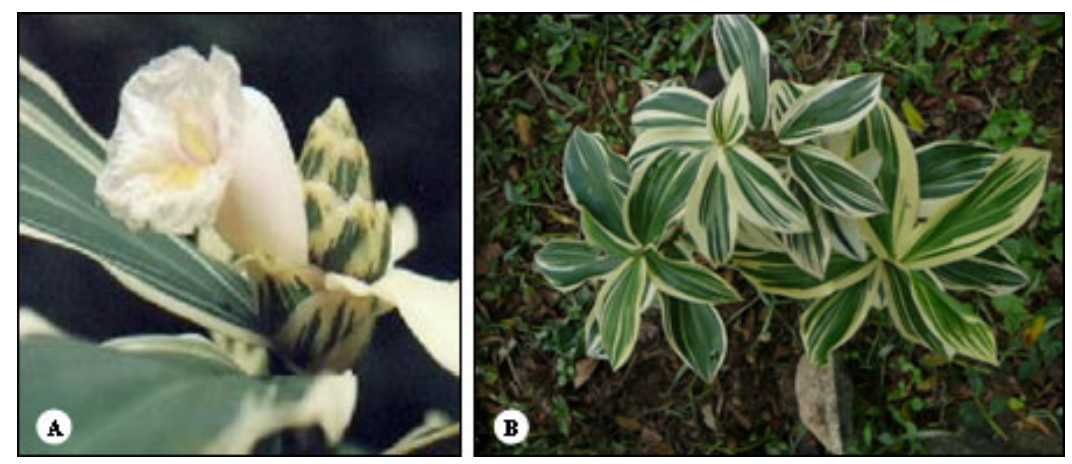

Figura 7. Costus arabicus variegata: a) inflorescência; b) aspecto geral da planta.

Figure 7. Costus arabicus variegata: a) inflorescence; b) overview of plant.

A coloração verde-acinzentada com largas faixas marrom, o número de hastes foliares emitidas por planta e a inflorescência basal, fusiforme e, laranja-avermelhada, de $C$. stenophyllus (Figura 8) foram as principais características que configuraram a espécie como planta para uso paisagís- tico. Esta espécie de hábito colunar, devido às suas hastes foliares eretas e folhas lineares, atingiu, em um ano de cultivo, altura de 2,0 m. A florada, embora restrita a pouco mais de três meses no ano, manteve as inflorescências por longo tempo.
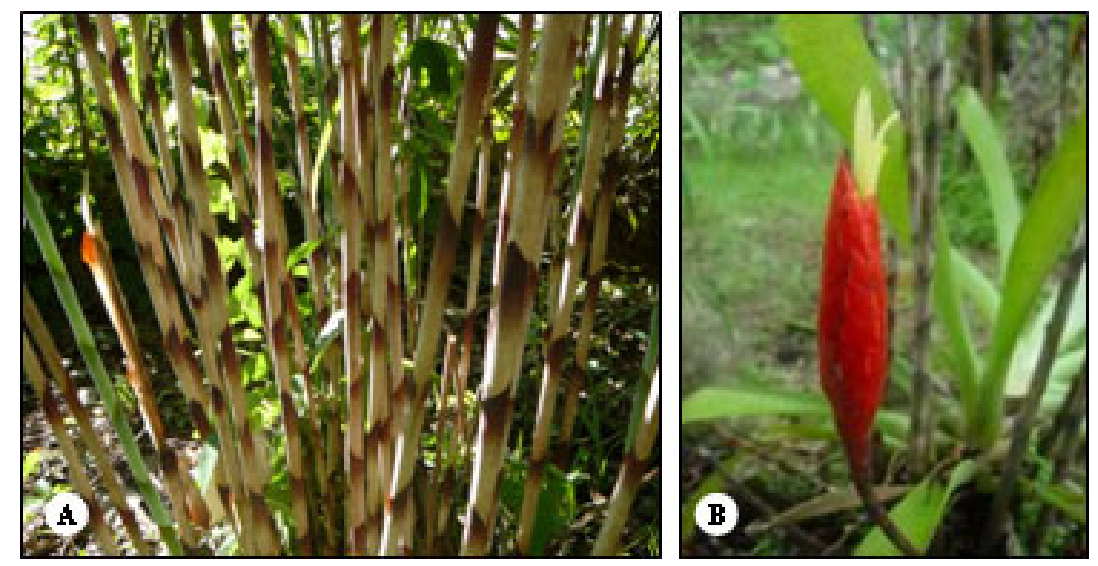

Figura 8. Costus stenophyllus: a) aspecto geral da planta; b) inflorescência.

Figure 8. Costus stenophyllus: a) overview of plant; b) inflorescence. 
O destaque ornamental de C. pulverulentus (Figura 9) deveu-se às suas inflorescências fusiformes, de tamanho significativo, que, embora em pequeno número, apresentam uma coloração vermelho alaranjada intensa, muito contrastante com a folhagem, compondo um conjunto mui-

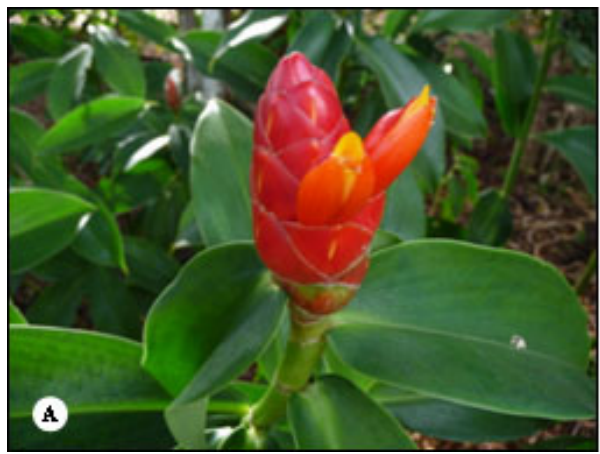

to atrativo.

A espécie foi avaliada como sendo de porte médio a alto e hábito colunar com poucas hastes foliares por planta. Entretanto, suas grandes folhas contribuem para uma razoável cobertura do solo.

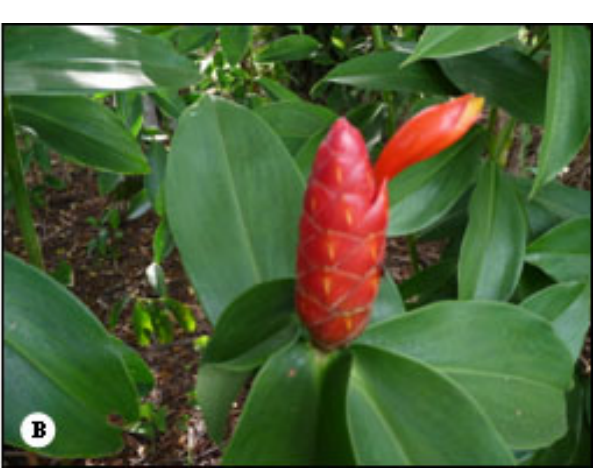

Figura 9. Costus pulverulentus: a) inflorescência; b) aspecto geral da planta. Figure 9. Costus pulverulentus: a) inflorescence; b) overview of plant.

C. comosus var. bakeri (Figura 10), embora frequentemente usado com flor de corte, também mostrou um possível uso como planta de jardim face à sua atraente inflorescência terminal, fusiforme, com até $15 \mathrm{~cm}$ de comprimento, com brácteas de textura firme, vermelho intenso e muito contrastante com as flores amarelas. Também foi muito evidente sua elegante e equilibrada combinação entre inflorescências e folhagem, esta última apresentando folhas grandes e medianamente largas, com nuances acinzentadas em seu verso.

Cheilocostus speciosus variegata (Figura 11) apresenta porte variando de médio a alto e hábito largo-colunar e hastes com organização espacial espiralada, refletindo-se em uma alta capacidade de recobrimento do solo, além de emissão de um número médio a alto de hastes foliares e inflorescências por planta, e floração persistente por longo período.

Todavia, o caráter mais atrativo da espécie são as folhas, com listas verde e creme, e hastes foliares variegadas com faixas verticais verde, creme e rosa, em perfeito conjunto com as inflorescência de brácteas justapostas cor de vinho e flores brancas e de longa durabilidade pós-colheita. Suas características permitem a indicação como planta para jardim e paisagismo e como flor de corte.
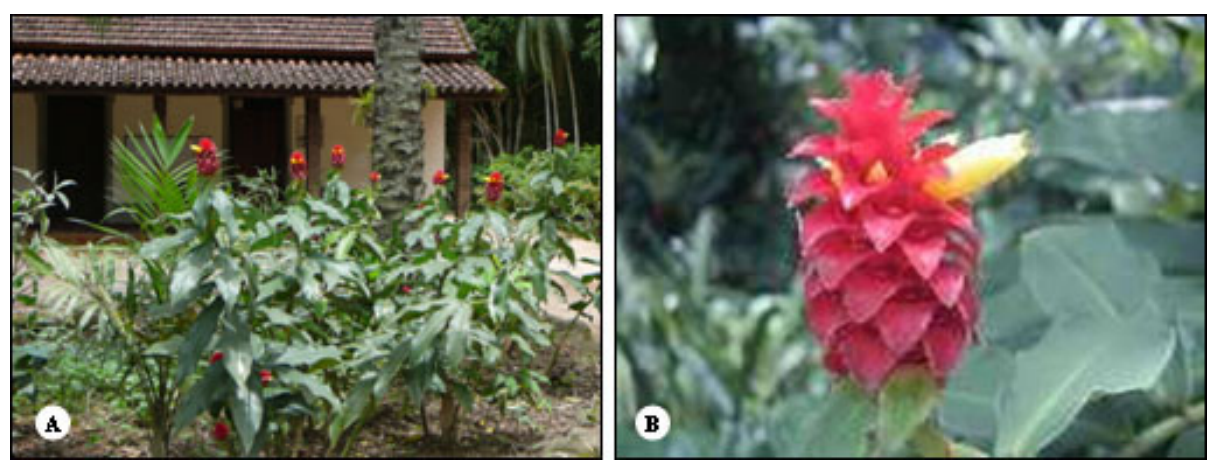

Figura 10. Costus comosus var. bakeri: a) aspecto geral da planta; b) inflorescência. Figure 10. Costus comosus var. bakeri: a) overview of plant; b) inflorescence.
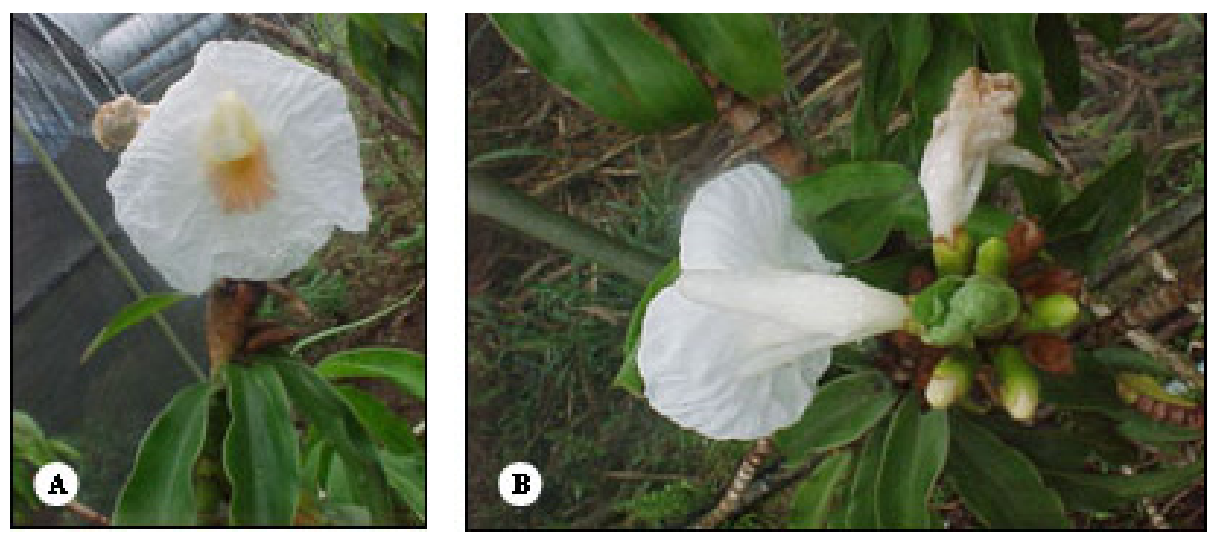

Figura 11. Cheilocostus speciosus variegata: a) inflorescência senescente; b) detalhe da flor.

Figure 11. Cheilocostus speciosus variegata: a) senescent inflorescence; b) flower detail. 
No caso de Dimerocostus strobilaceus (Figura 12), a grande altura da planta e o hábito colunar, conferido pelo elevado número de hastes eretas foliares com folhas variando de elípticas a lineares foram os aspectos mais marcantes. O diâmetro das hastes foliares e a lígula de cor verde-marrom contrastante nessas estruturas compõem um interessante conjunto paisagístico. Ademais, a espécie apresentou inflorescência grande, com brácteas levemente justapostas de coloração marrom opaca e flores brancas, efêmeras, de grande tamanho. A espécie pode ser indicada para uso como planta de jardim e paisagismo. Em função das características das hastes, esta espécie também pode ser recomendada para uso como haste de corte.

Consideradas as características de porte e arquitetura da planta, manutenção de folhas verdes ou variegadas nas hastes, capacidade de recobrimento do solo, coloração e dimensões das hastes foliares e folhas e as características da floração como persistência, período e número de inflorescências produzidas por ciclo, foram confirmados os resultados de GONÇALVES et al. (2005) de serem adequadas ao cultivo em vasos para interiores, as espécies Costus ma- lortieanus, C. lasius e C. arabicus variegata. Neste trabalho, acrescenta-se a esse uso a espécie C. productus. Entretanto, em face da análise dessas mesmas características, considera-se seu plantio em canteiros ou recipientes que contenham um grande volume de solo ou substrato, podendo ser recomendadas para o cultivo em vasos destinados à ornamentação em áreas externas as espécies $C$. pictus, $C$. stenophyllus e Cheilocostus speciosus variegata.

Os resultados obtidos permitiram a identificação de Costus lasius, C. productus, C. arabicus, C. stenophyllus, C. comosus var. bakeri, C. scaber, Cheilocostus speciosus variegata e Dimerocostus strobilaceus como espécies adequadas ao comércio como flor de corte. Embora a espécie Cheilocostus speciosus variegata tenha requerido a retirada das flores senescentes das inflorescências, este não pode ser considerado um fator limitante à sua indicação de uso.

Adicionalmente, as hastes foliares de Costus stenophyllus, C. pictus, Cheilocostus speciosus variegata e Dimerocostus strobilaceus podem ser comercializadas como hastes foliares cortadas (Figura 13), ampliando-se o mercado de produtos da floricultura.
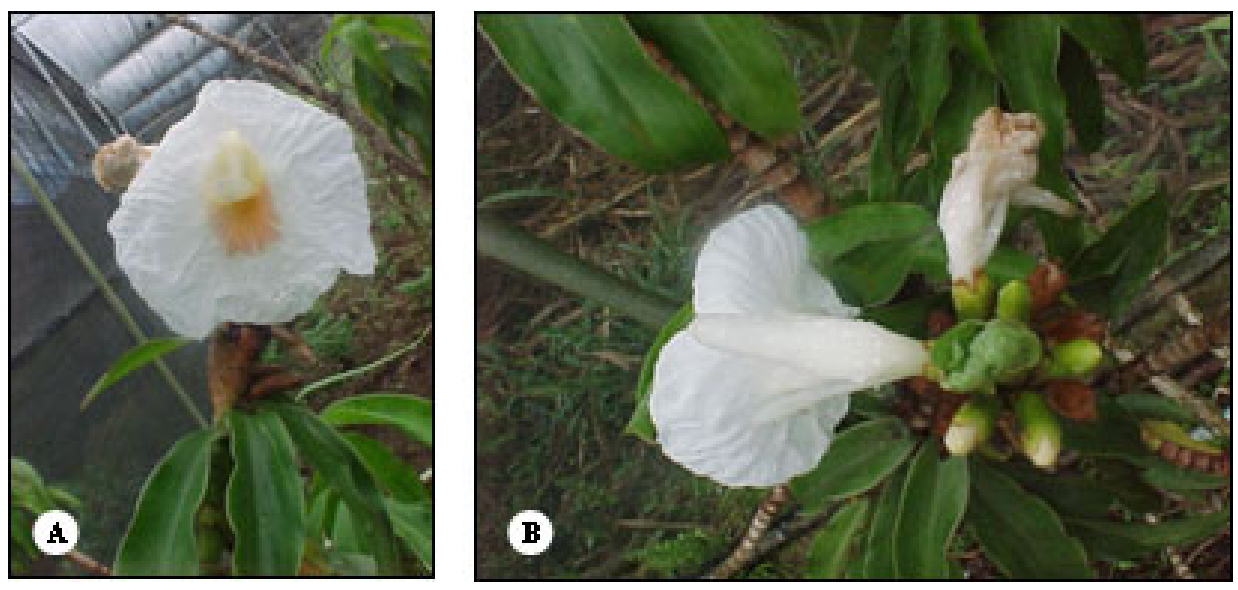

Figura 12. Dimerocostus strobilaceus: a) detalhe da flor; b) inserção das flores.

Figure 12. Dimerocostus strobilaceus: a) flower detail; b) insertion of the flower.

$\mathbf{A}$

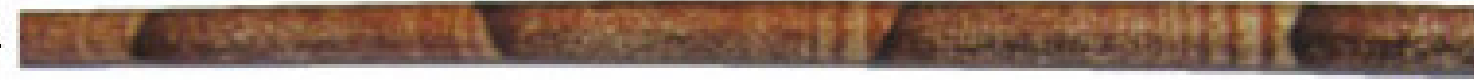

B

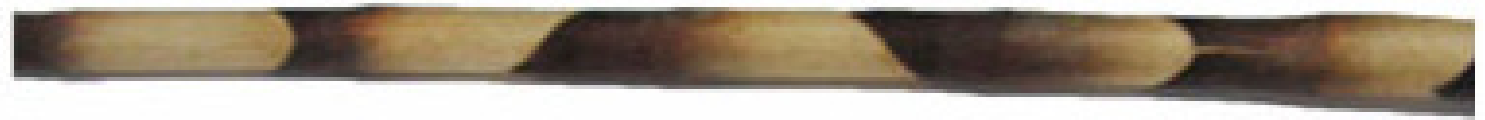

c

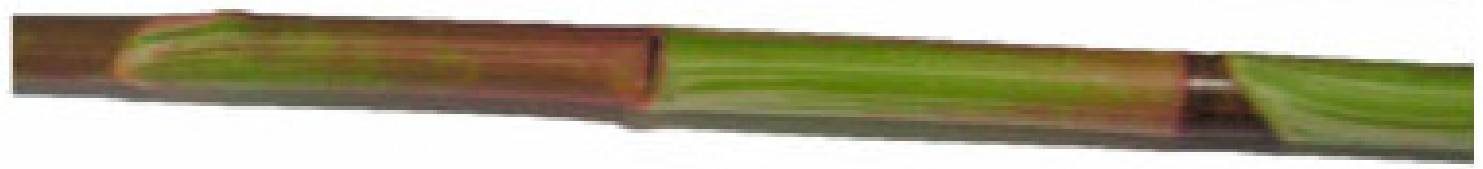

D

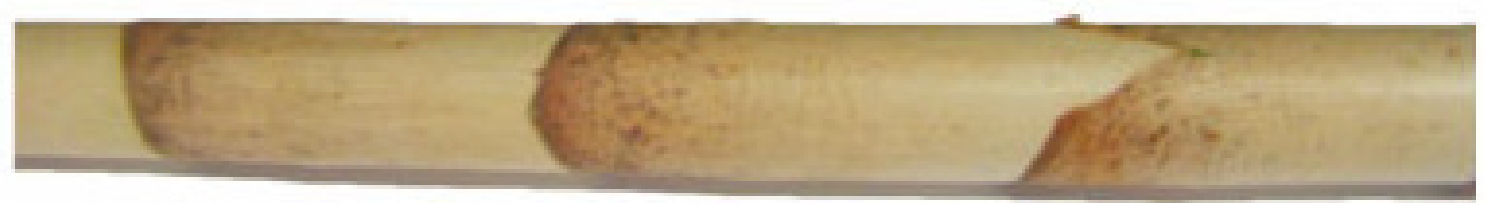

Figura 13. Caules de corte: a) Costus pictus; b) Costus stenophyllus; c) Cheilocostus speciosus variegata; d) Dimerocostus strobilaceus.

Figure 13. Cut stems: a) Costus pictus; b) Costus stenophyllus; c) Cheilocostus speciosus variegata; d) Dimerocostus strobilaceus. 


\section{CONCLUSÕES}

Observadas as condições experimentais adotadas na condução deste trabalho, conclui-se que:

1.Costus lasius, C. productus, C. malortieanus, C. pictus, C. arabicus variegata, C. stenophyllus, C. pulverulentus, C. comosus var. bakeri, Cheilocostus speciosus variegata e Dimerocostus strobilaceus são espécies adequadas para plantios em jardins;

2. Costus lasius, C. productus, C. malortieanus e C. arabicus variegata são espécies adequadas para cultivo em vasos destinados a interiores;

3. Costus pictus, C. stenophyllus Cheilocostus speciosus variegata e Dimerocostus strobilaceus são espécies adequadas para cultivo em canteiros ou grandes recipientes;

4. Costus lasius, C. productus, C. arabicus, C. stenophyllus, C. comosus var. bakeri, C. scaber, Cheilocostus speciosus variegata e Dimerocostus strobilaceus são espécies adequadas para a produção de flores de corte;

5. Costus stenophyllus, C. pictus, Cheilocostus speciosus variegata e Dimerocostus strobilaceus são espécies que podem ser comercializadas como hastes foliares cortadas.

\section{REFERÊNCIAS}

GONÇALVES, C.; CASTRO, C. E. F.; AZEVEDO FILHO, J. A.; TAGLIACOZZO, G. M. D. Evaluation of Costus species and their use as indoor potted-plants. Acta Horticulturae, Leuven, Bélgica, v. 683, p. 319-325, 2005.

HEYWOOD, V. H. Flowering plants of the world. Oxford University Press. New York. 1993. 335 pp.

KRESS, W. J. The phylogeny and classification of the Zingiberales. Ann. Missouri Bot. Gard. 77: 698-721, 1990.

MAAS, P. J. M. Flora Neotropica. Monograf $n^{\circ} 8$. Costoideae (Zingiberaceae). New York. 8: 1-139, 1972.

MAAS, P. J. M. Flora Neotropica. Costoideae (Zingiberaceae). Additions to Flora Neotropica Monograf $\mathrm{n}^{\circ} 8$. New York, v. 18, p. 1-52, 1976.

SPECHT, C. D. \& STEVENSON, D. W. A new phylogenybased generic classification of Costaceae (Zingiberales). Taxon, v. 55, n. 1, p. 153-163, 2006.

TOMLINSON, P.B. Phylogeny of the Scitamineae - Morphological and anatomical considerations. Evolution, Miami, v. 16, p. 192-213, 1962. 